\title{
Synthesis of High cis-Polybutadiene in Styrene Solution with Neodymium-Based Catalysts: Towards the Preparation of HIPS and ABS via In Situ Bulk Polymerization
}

\author{
Ramón Díaz de León, Florentino Soriano Corral, \\ Francisco Javier Enríquez-Medrano, Gabriela Bosques Ibarra, \\ Patricia de León Martínez, Francisco Hernández Gámez, \\ Héctor Ricardo López-González, and Luis Francisco Ramos de Valle
}

Centro de Investigación en Química Aplicada, Blvd. Enrique Reyna No. 140, San José de los Cerritos, 25294 Saltillo, COAH, Mexico

Correspondence should be addressed to Ramón Díaz de León; ramon.diazdeleon@ciqa.edu.mx and Florentino Soriano Corral; florentino.soriano@ciqa.edu.mx

Received 21 July 2016; Accepted 13 October 2016

Academic Editor: Atsushi Sudo

Copyright ( 2016 Ramón Díaz de León et al. This is an open access article distributed under the Creative Commons Attribution License, which permits unrestricted use, distribution, and reproduction in any medium, provided the original work is properly cited.

\begin{abstract}
In a first step, 1,3-butadiene was selectively polymerized at $60^{\circ} \mathrm{C}$ in styrene as solvent using $\mathrm{NdV}_{3} / \mathrm{DIBAH} / \mathrm{EASC}$ as the catalyst system. The catalyst system activation process, the addition order of monomers and catalyst components, and the molar ratios $[\mathrm{Al}] /[\mathrm{Nd}]$ and $[\mathrm{Cl}] /[\mathrm{Nd}]$ were studied. The catalyst system allowed the selective 1,3-butadiene polymerization, reaching conversions between 57.5 and $88.1 \%$ with low polystyrene contents in the order of 6.3 to $15.4 \%$. Molecular weights ranging from 39,000 to $150,000 \mathrm{~g} / \mathrm{mol}$ were obtained, while cis-1,4 content was found in the interval of 94.4 to $96.4 \%$. On the other hand, the glass transition temperatures of synthesized materials were established in the range of -101.9 to $-107.4^{\circ} \mathrm{C}$, explained by the presence of polystyrene segments in the polybutadiene chains; in the same sense, the polybutadienes did not show the typical melting endotherm of high cis-polybutadienes. In a second step, the resulting styrene/high cis-1,4 polybutadiene solutions were used to synthesize ABS (adding a fraction of acrylonitrile monomer) and HIPS via in situ bulk polymerizations and the results were discussed in terms of morphological development, molecular parameters, dynamical mechanical behavior, and mechanical properties.
\end{abstract}

\section{Introduction}

The 4f-orbital electrons of neodymium- (Nd-) based catalyst systems, either binary $\left(\mathrm{NdCl}_{3} \cdot n \mathrm{~L} /\right.$ aluminum alkyl, where $\mathrm{L}=$ ligand) or ternary $\left(\mathrm{Nd}\right.$ (carboxylated) ${ }_{3} /$ aluminum alkyl/aluminum alkyl halide), constitute an effective option for the stereospecific polymerization of 1,3-dienes [1]. The ionic size and coordination abilities of the Nd-based catalyst systems, besides controlling the identity of the isomers cis-1,4 and trans-1,4, also produce high molecular weight polymers and exhibit high catalytic activity [2].

It is noteworthy that the ternary catalyst systems provide greater versatility than the binary catalyst systems; even under certain reaction conditions it is possible to obtain narrow molecular weight distributions (MWD) and to produce copolymers with other 1,3-dienes and polar monomers [3]. The stereospecific polymerization of 1,3-butadiene with terna ry and binary Nd-based catalyst systems can be carried out in a wide scenario of solvents. For instance, Duvakina and Monakov performed the 1,3-butadiene polymerization using the binary catalyst system $\mathrm{NdCl}_{3} \cdot 3 \mathrm{TBP} / \mathrm{Mg}\left(n-\mathrm{C}_{4} \mathrm{H}_{9}\right)(i-$ $\left.\mathrm{C}_{8} \mathrm{H}_{17}\right)$ in chlorobenzene, toluene, and cyclohexane; they found that the nature of the aromatic solvent used influences the microstructure of the resulting polybutadienes (PB) [4]. Monteil et al. studied different catalyst systems in heptane and toluene, all of them based on the complex $\mathrm{Nd}\left[\mathrm{N}\left(\mathrm{SiMe}_{3}\right)_{2}\right]_{3}$ and activated with methylaluminoxane (MAO) or boron compound/triisobutylaluminum (TIBA) [5]. This work revealed that all catalyst systems provided PB with high molecular weight, although the stereospecificity and catalytic 
activity depended on the activator and solvent used. High cis-1,4 content was obtained only with boron compound/ TIBA in heptane, and the activity was lower in toluene than in heptane. Friebe et al. [6] also investigated the influence of different solvents in the 1,3-butadiene polymerization with Ziegler catalyst based on $\mathrm{Nd}$ versatate $\left(\mathrm{NdV}_{3}\right)$ / diisobutylaluminium hydride (DIBAH)/ethylaluminium sesquichloride (EASC) and they confirmed that the catalytic activity was reduced in aromatic media, but cis-1,4 content was higher in toluene and ter-butyl benzene than in hexane.

The versatility of the $\mathrm{Nd}$-based catalyst systems has enabled the synthesis of PB even using styrene as a solvent, as reported by Hsieh and Yeh [7] with the binary system $\mathrm{NdX}_{3} \cdot n \mathrm{D} / \mathrm{AlR}_{3}$. The relevance of this feature of $\mathrm{Nd}$-based catalyst systems is the fact that the reaction product, styrene/PB solution, can be used to produce toughened styrenic resins through the in situ bulk polymerization process. This process consists first in the selective polymerization of 1,3-butadiene using styrene as solvent with $\mathrm{Nd}$-based catalyst system, leading to a styrene/high cis-1,4 PB solution. Subsequently, the acrylonitrile monomer is added to the solution and, by means of free radical polymerization, poly(acrylonitrilebutadiene-styrene) (ABS) is obtained [8]. To obtain highimpact polystyrene (HIPS), the process is carried out in the same way but without acrylonitrile [9]. With this process, it is possible to overcome two main disadvantages in a typical process of toughened styrenic resins manufacturing: (i) expensive work-up to isolate the PB by stripping with steam or by direct evaporation from its polymerization process and (ii) $\mathrm{PB}$ dissolving process in the monomer which requires long time and effective devices. In addition, the preparation of toughened styrenic resins has been focused on the use of high cis-1,4 PB as the rubbery component to obtain HIPS or ABS with appropriate features for a high performance [10,11].

In spite of the technological relevance of $\mathrm{Nd}$-based catalyst systems to obtain high cis-1,4 PB for toughened styrenic resins applications via in situ bulk polymerization process, there are only a few studies reported in the literature. For instance, Hattori and Kitagawa showed the ability of the ternary system $\mathrm{Nd}$ (phosphate) ${ }_{3} / \mathrm{DIBAH} / \mathrm{EASC}$ to polymerize 1,3-butadiene in styrene, where styrene was substantially polymerized at a very low conversion degree of less than $1.6 \%$, and the HIPS obtained based on a dimer of $\alpha$-methylstyrene showed particle sizes of about $2 \mu \mathrm{m}$ and Izod impact strength in the range of $13-16 \mathrm{~kg} \cdot \mathrm{cm} / \mathrm{cm}$ [9]. Hu et al. [8] employed the catalyst system $\mathrm{Nd}\left(\mathrm{P}_{507}\right)_{3} / \mathrm{DIBAH} /$ EASC to obtain high cis-1,4 PB/styrene solutions proper for the synthesis of ABS. In that work, three different initiators with diverse peroxidic functionality were evaluated and the resulting materials showed mono and bimodal particle size distribution exhibiting impact strength from 42.2 to $335.9 \mathrm{~J} / \mathrm{m}$, respectively. On the other hand, information concerning the 1,3-butadiene polymerization in styrene using $\mathrm{NdV}_{3} / \mathrm{DIBAH} / \mathrm{EASC}$ to produce both HIPS and ABS via in situ bulk polymerization was reported in some patents but the detailed analytical studies are not available $[8,12]$.

In this work, the effect of different aspects of the catalyst system based on $\mathrm{NdV}_{3} / \mathrm{DIBAH} / \mathrm{EASC}$ preparation is reported and systematically discussed, such as addition order of components for in situ and ageing preformation process for catalyst activation and ageing time as well as the $[\mathrm{Al}] /[\mathrm{Nd}]$ and $[\mathrm{Cl}] /[\mathrm{Nd}]$ molar ratios on the monomer conversion, microstructure, and physicochemical characteristics of the resulting $\mathrm{PB}$ obtained with the ternary catalyst system $\mathrm{NdV}_{3} / \mathrm{DIBAH} / \mathrm{EASC}$ in styrene as reaction medium. Moreover, using several $\mathrm{PB} /$ styrene solutions and via in situ bulk polymerization by a free radical process, different toughened styrenic resins were obtained and analyzed.

\section{Experimental Study}

2.1. Materials. All manipulations were carried out in an MBRAUN glove box or under inert atmosphere using a dual vacuum-nitrogen line and standard Schlenk techniques. The catalyst, neodymium versatate $\left(\mathrm{NdV}_{3}-50\right)$, was obtained from Rhodia Group. Styrene and cyclohexane were purchased from Aldrich and distilled twice in the presence of sodium prior to their use. $1.0 \mathrm{M}$ solutions in hexane of DIBAH and EASC with $97 \%$ purity were acquired from Aldrich. 1,3-Butadiene was purchased from Aldrich and it was purified by passing it through a $4 \AA$ activated molecular sieve and alumina. To represent the molar concentrations of the reactants studied, $\mathrm{NdV}_{3}$ is abbreviated as [Nd], styrene as [S], 1,3-butadiene as [B], DIBAH as [Al], and EASC as $[\mathrm{Cl}$. Acrylonitrile (AN), tert-butyl peroxybenzoate (TBPB), and tert-dodecylmercaptan (TDM) were also acquired from Aldrich. 2,5-Dimethyl-2,5-di(2-ethylhexanoylperoxy)hexane (Luperox-256) and benzoyl peroxide (BPO) were obtained from Arkema and Promotores y Catalizadores Orgánicos de México, respectively. BPO was crystallized from ethanol prior to its use. Mineral oil from PROQUISA México was used as received.

2.2. 1,3-Butadiene Polymerizations in Styrene. Isothermal polymerizations using the recipes reported in Table 1 were carried out under a dry nitrogen atmosphere in a $1 \mathrm{~L}$ stainless steel Parr reactor equipped with a turbine-type mechanical stirrer. The reaction temperature was controlled by means of electrical resistance and flow of cold water through an internal tubing coil operated by means of a PID controller. Prior to usage, the reactor was heated up to $150^{\circ} \mathrm{C}$ and several vacuum and nitrogen cycles were carried out in order to purify the reactor and to ensure complete removal of moisture and air; then it was cooled to room temperature. A typical polymerization procedure carried out in runs R1 to R5 and R11 is described as follows: the desired volume of styrene was added to the reactor and it was heated to the set temperature under constant stirring of $100 \mathrm{rpm}$; thereafter, the reactor was filled with 1,3-butadiene and the catalyst system was added to the reactor in the next order by means of a syringe, (i) DIBAH, (ii) $\mathrm{NdV}_{3}$, and (iii) EASC. Finally, acidified methanol was added in order to stop the polymerization reaction. The obtained polymer was stabilized with Irganox 1076, precipitated in methanol, and dried under vacuum at $25^{\circ} \mathrm{C}$. The polymerization procedure carried out in runs R6 to R10 and R12 is described as follows: initially the catalyst system was prepared in a glass vial containing a rubber septum; then, the following reactants were added in the mentioned 
TABLE 1: Recipes for coordination polymerization of 1,3-butadiene in styrene using the catalyst system $\mathrm{NdV}_{3} / \mathrm{DIBAH} / \mathrm{EASC}$.

\begin{tabular}{|c|c|c|c|c|c|c|c|c|c|c|}
\hline Run & {$[\mathrm{Al}] /[\mathrm{Nd}]$} & {$[\mathrm{Cl}] /[\mathrm{Nd}]$} & $V_{S}(\mathrm{~mL})$ & Addition order & $x^{\mathrm{d}}(\%)$ & $\bar{M}_{n}^{\mathrm{e}}(\mathrm{g} / \mathrm{mol})$ & $\mathrm{PDI}^{\mathrm{e}} \bar{M}_{w} / \bar{M}_{n}$ & PS $^{\mathrm{f}}$ content $(\%)$ & cis-1, $4^{\mathrm{f}}(\%)$ & $T_{g}{ }^{\mathrm{g}}\left({ }^{\circ} \mathrm{C}\right)$ \\
\hline $\mathrm{R} 1$ & 20 & 0.62 & 200 & $\mathrm{~S}+\mathrm{B}+\mathrm{Al}+\mathrm{Nd}+\mathrm{Cl}$ & 66.8 & 19000 & 7.5 & 24.4 & 95.8 & -104.8 \\
\hline R2 & 20 & 0.62 & 300 & $\mathrm{~S}+\mathrm{B}+\mathrm{Al}+\mathrm{Nd}+\mathrm{Cl}$ & 71.2 & 61000 & 4.1 & 14.4 & 96.1 & -104.8 \\
\hline R3 & 30 & 0.62 & 300 & $\mathrm{~S}+\mathrm{B}+\mathrm{Al}+\mathrm{Nd}+\mathrm{Cl}$ & 57.5 & 38000 & 5.7 & 13.2 & 96.1 & -103.3 \\
\hline $\mathrm{R} 4^{\mathrm{a}}$ & 20 & 0.62 & 200 & $\mathrm{~S}+\mathrm{B}+\mathrm{Cl}+\mathrm{Nd}+\mathrm{Al}$ & - & - & - & - & - & - \\
\hline R5 & 20 & 0.62 & 200 & $\mathrm{~S}+\mathrm{Al}+\mathrm{Nd}+\mathrm{Cl}+\mathrm{B}$ & 85.3 & 150000 & 3.3 & 7.7 & 96.4 & -107.4 \\
\hline R6 & 20 & 0.62 & 300 & $\mathrm{~S}+\mathrm{B}+(\mathrm{Al}+\mathrm{Nd}+\mathrm{Cl})^{\mathrm{c}}$ & 67.2 & 88000 & 4.0 & 10.0 & 96.4 & -104.9 \\
\hline R7 & 20 & 0.62 & 300 & $\mathrm{~S}+\mathrm{B}+(\mathrm{Cl}+\mathrm{Nd}+\mathrm{Al})^{\mathrm{c}}$ & 70.0 & 86000 & 5.6 & 14.3 & 96.5 & -106.4 \\
\hline $\mathrm{R} 8$ & 30 & 0.62 & 300 & $\mathrm{~S}+\mathrm{B}+(\mathrm{Al}+\mathrm{Nd}+\mathrm{Cl})^{\mathrm{c}}$ & 60.1 & 42000 & 4.5 & 10.7 & 94.4 & -104.2 \\
\hline R9 & 30 & 0.62 & 300 & $\mathrm{~S}+\mathrm{B}+(\mathrm{Cl}+\mathrm{Nd}+\mathrm{Al})^{\mathrm{c}}$ & 64.7 & 27000 & 8.4 & 11.7 & 94.8 & -104.3 \\
\hline $\mathrm{R} 10$ & 30 & 0.90 & 300 & $\mathrm{~S}+\mathrm{B}+(\mathrm{Al}+\mathrm{Nd}+\mathrm{Cl})^{\mathrm{c}}$ & 67.2 & 54000 & 4.5 & 9.2 & 96.0 & -103.5 \\
\hline $\mathrm{R} 11^{\mathrm{b}}$ & 20 & 0.62 & 600 & $\mathrm{~S}+\mathrm{Al}+\mathrm{Nd}+\mathrm{Cl}+\mathrm{B}$ & 88.1 & 125000 & 2.8 & 6.3 & 96.5 & N.D. ${ }^{h}$ \\
\hline $\mathrm{R} 12^{\mathrm{b}}$ & 30 & 0.62 & 600 & $\mathrm{~S}+\mathrm{B}+(\mathrm{Al}+\mathrm{Nd}+\mathrm{Cl})^{\mathrm{c}}$ & 64.8 & 39000 & 3.4 & 11.0 & 96.1 & N.D. ${ }^{h}$ \\
\hline
\end{tabular}

Note: isothermal polymerizations were performed in styrene at $60^{\circ} \mathrm{C}$ for $3.5 \mathrm{~h} ; N_{\mathrm{B}}=0.5084 \mathrm{~mol} ; N_{\mathrm{Nd}}=0.20 \mathrm{mmol}$.

${ }^{a}$ The polymerization was not possible in this way.

${ }^{\mathrm{b}}$ Polymerizations at $60^{\circ} \mathrm{C}$ for $5 \mathrm{~h} ; N_{\mathrm{B}}=1.5252 \mathrm{~mol} ; N_{\mathrm{Nd}}=0.60 \mathrm{mmol}$.

${ }^{\mathrm{c} C}$ Catalyst system aged at $30^{\circ} \mathrm{C}$ for $3 \mathrm{~min}$ before use.

${ }^{\mathrm{d}}$ Conversion.

${ }^{\mathrm{e}}$ Determined by size exclusion chromatography (SEC) with polystyrene standards.

${ }^{\mathrm{f}} \mathrm{PS}$ content determined by ${ }^{1} \mathrm{H}$ NMR and cis-percentage determined by ${ }^{13} \mathrm{C}$ NMR.

${ }^{\mathrm{g}}$ Determined by differential scanning calorimetry (DSC).

${ }^{\mathrm{h}}$ Not determined.

TABLE 2: Recipes for in situ bulk polymerizations to obtain ABS using the run R11 and different properties obtained.

\begin{tabular}{|c|c|c|c|c|c|c|c|c|}
\hline Sample & $\begin{array}{l}{[\mathrm{R} 11]_{0}{ }^{\mathrm{a}}} \\
(\mathrm{wt} . \%)\end{array}$ & $\begin{array}{c}{[\mathrm{L}-256]_{0}} \\
(\mathrm{wt} . \%)\end{array}$ & $\begin{array}{c}{[\mathrm{TDM}]_{0}} \\
(\mathrm{wt} . \%)\end{array}$ & $\mathrm{Gel}^{\mathrm{b}}(\%)$ & $\mathrm{GDl}^{\mathrm{b}}(\%)$ & $\begin{array}{c}M_{n \text { matrix }}{ }^{\mathrm{c}} \\
(\mathrm{g} / \mathrm{mol})\end{array}$ & $\mathrm{PDI}^{\mathrm{c}} M_{w} / M_{n}$ & $\begin{array}{l}\text { Impact } \\
\text { strength }^{\mathrm{d}} \\
(\mathrm{J} / \mathrm{m})\end{array}$ \\
\hline ABS-1 & 8 & 0.022 & 0.11 & 34.7 & 329 & 136000 & 2.95 & 36 \\
\hline ABS-2 & 8 & 0.066 & 0.33 & 37.2 & 365 & 98000 & 2.13 & 23 \\
\hline
\end{tabular}

Stage 1-mass (sl-m): $[\mathrm{S}]_{0}=71.3 \mathrm{wt} . \% ;[\mathrm{AN}]_{0}=20.7 \mathrm{wt}-\% ;[\text { mineral oil }]_{0}=5 \mathrm{wt}-\% ; T_{\mathrm{sl}-\mathrm{m}}=90^{\circ} \mathrm{C} ; \mathrm{rpm}=60$.

Stage 2-mass (s2-m): $[\mathrm{PBTB}]_{0}=0.1 \mathrm{wt}-\% ; T_{\mathrm{s} 2-\mathrm{m}}=150^{\circ} \mathrm{C} ; T_{\mathrm{s} 2-\mathrm{m}}=15 \mathrm{~h}$.

${ }^{a}$ Rubber corresponding to run R11.

${ }^{\mathrm{b}}$ Grafting degree and gel content were obtained by gravimetry.

${ }^{c}$ Determined by size exclusion chromatography (SEC) with polystyrene standards.

${ }^{\mathrm{d}}$ Determined by Izod impact notched.

order: (i) cyclohexane $=10 \mathrm{~mL}$, (ii) DIBAH $=4 \mathrm{~mL}$ ( $1 \mathrm{M}$ in hexane), (iii) $\mathrm{NdV}_{3}=0.35 \mathrm{~mL}$ (0.58 $\mathrm{M}$ in hexane), and (iv) EASC $=0.25 \mathrm{~mL}(0.5 \mathrm{M}$ in cyclohexane). The catalyst system was aged at $30^{\circ} \mathrm{C}$ for $3 \mathrm{~min}$ prior to usage. On the other hand, styrene was added at the reactor and it was heated to $60^{\circ} \mathrm{C}$; then 1,3-butadiene was introduced into the reactor and finally the aged catalyst system was added to the reactor with a syringe. The deactivation and purification steps were identical to those previously described. In R11 and R12, the same methodologies previously described were used; however, in both runs, several samples of the reaction mixture were taken in order to evaluate gravimetrically the conversion and composition evolution by ${ }^{1} \mathrm{H}$ Nuclear Magnetic Resonance (NMR). Likewise, the polymerizations were deactivated by addition of $3.45 \mathrm{~g}$ of acetylacetone and $0.1 \mathrm{~g}$ of Irganox 1076 as reported in literature [12]. After that, the reactor was cooled to room temperature and the internal pressure was reduced to $510 \mathrm{mmHg}$ and kept there for $45 \mathrm{~min}$ in order to remove the unreacted 1,3-butadiene. To eliminate reaction residues and by-products of the deactivation, the polymer solution was filtered and transferred to a second reactor for the in situ bulk polymerizations to produce ABS and HIPS.

2.3. In Situ Bulk Polymerizations for ABS and HIPS. The different recipes for the synthesized ABS and HIPS are shown in Tables 2 and 3; all polymerizations were carried out under a nitrogen atmosphere in a $1 \mathrm{~L}$ stainless steel Parr reactor disposed with an anchor-turbine stirrer. A representative procedure for ABS (also applicable for HIPS) is described as follows: in the first mass stage, the rubber concentration in the solution of styrene (R11) and the azeotropic composition of styrene/acrylonitrile was adjusted (in HIPS, the rubber concentration was adjusted through the addition of styrene (R12)). Thereafter, luperox-256, TDM, and mineral oil were introduced in appropriate amounts into the reactor (in HIPS, only $\mathrm{BPO}$ was added) and the temperature was increased to $90^{\circ} \mathrm{C}$ at a heating rate of $3^{\circ} \mathrm{C} / \mathrm{min}$. The reaction mixture was then kept at $90^{\circ} \mathrm{C}$ and $60 \mathrm{rpm}$ (for HIPS the conditions 
TABLE 3: Recipes for in situ bulk polymerizations to obtain HIPS using the run R12 and different properties obtained.

\begin{tabular}{lccccccc}
\hline Sample & {$[\mathrm{R} 12]_{0}{ }^{\mathrm{a}}$ (wt.\%) } & {$\left[\mathrm{PS}_{\text {homopolymer }}\right]_{0}^{\mathrm{b}}(\mathrm{wt} . \%)$} & $\mathrm{GD}^{\mathrm{c}}(\%)$ & $\mathrm{Gel}^{\mathrm{c}}(\%)$ & $M_{n \text { matrix }}{ }^{\mathrm{d}}(\mathrm{g} / \mathrm{mol})$ & $\mathrm{PDI}^{\mathrm{d}} M_{w} / M_{n}$ & $\mathrm{Impact} \mathrm{strength}^{\mathrm{e}}(\mathrm{J} / \mathrm{m})$ \\
\hline HIPS-1 & 7 & 0 & 69.0 & 10.5 & 71000 & 2.31 & 21 \\
HIPS-2 & 7 & 5 & 64.5 & 11.4 & 69000 & 2.62 & 17 \\
\hline
\end{tabular}

Stage 1-mass (s1-m): $[\mathrm{S}]_{0}=93 \mathrm{wt}-\% ;[\mathrm{BPO}]_{0}=0.1 \mathrm{wt}-\% ; T_{\text {s1-m }}=90^{\circ} \mathrm{C} ; \mathrm{rpm}=40$.

Stage 2-mass (s2-m): $[\text { PBTB }]_{0}=0.1 \mathrm{wt}-\% ; T_{\mathrm{s} 2-\mathrm{m}}=150^{\circ} \mathrm{C} ; T_{\mathrm{s} 2-\mathrm{m}}=15 \mathrm{~h}$.

${ }^{a}$ Rubber corresponding to run R12.

${ }^{\mathrm{b}}$ Polystyrene homopolymer with $M_{n}=66000 \mathrm{~g} / \mathrm{mol}$ added at the beginning of the in situ bulk polymerizations.

${ }^{c} \mathrm{Grafting}$ degree and gel content were obtained by gravimetry.

${ }^{\mathrm{d}}$ Determined by size exclusion chromatography (SEC) with polystyrene standards.

${ }^{\mathrm{e}}$ Determined by Izod impact notched.

were $90^{\circ} \mathrm{C}$ and $40 \mathrm{rpm}$ ) until the final conversion reached $\geq 35 \%$ in order to ensure the occurrence of the phase inversion phenomenon. Once the reaction has reached $35 \%$ conversion, the TBPB was added to the reaction mixture as the initiator for the second mass stage, and the reaction mixture was then introduced into glass ampoules and left for $15 \mathrm{~h}$ at $150^{\circ} \mathrm{C}$ $\left(T_{\mathrm{s} 2-\mathrm{m}}\right)$ and $7 \mathrm{~kg} / \mathrm{cm}^{2}$ until the polymerization is finished. The product was extracted and milled for further characterization.

2.4. Size Exclusion Chromatography (SEC). The molecular weights of the samples were determined by SEC using a PLGel mixed column in a Hewlett-Packard instrument (HPLC series 1100) equipped with a refractive index detector. Calibration was carried out with polystyrene (PS) standards and tetrahydrofuran (HPLC grade from Aldrich) was used as eluent at a flow rate of $1 \mathrm{~mL} / \mathrm{min}$.

2.5. Nuclear Magnetic Resonance (NMR). PB samples were analyzed by ${ }^{1} \mathrm{H}$ and ${ }^{13} \mathrm{C}$ NMR in order to calculate their microstructures; the analyses were performed in a JEOL Eclipse- $300 \mathrm{MHz}$ spectrometer at room temperature. $\mathrm{CDCl}_{3}$ was used as the solvent. 1,2-PB, from the total of 1,2 and 1,4 $\mathrm{PB}$, was determined via ${ }^{1} \mathrm{H}$ NMR by integrating the area of olefinic protons located in the range from 4.8 to $5.7 \mathrm{ppm}$, while the ratio cis/trans was calculated by ${ }^{13} \mathrm{C}$ NMR (proton gated decoupling no-NOE experiments) by integrating the area of aliphatic carbons located in the range from 27 to $33 \mathrm{ppm}$ [13]. PS content in the samples was determined by integrating and comparing the aromatic protons located in the range from 6.4 to $7.5 \mathrm{ppm}$. As examples, Figures 1 and 2 show the ${ }^{1} \mathrm{H}$ and ${ }^{13} \mathrm{C}$ NMR spectra, respectively, corresponding to run 7 in order to explain the signals assignation, where $1,4-\mathrm{PB}=(\mathbf{a})-0.5(\mathbf{b}), 1,2-\mathrm{PB}=(\mathbf{b}), \mathrm{PS}=(\mathbf{c}), c i s-1,4 \mathrm{~PB}=(\mathbf{d})$ and trans $-1,4 \mathrm{~PB}=(\mathbf{e})$.

2.6. Gel Content and Grafting Degree (GD). Samples of $0.5 \mathrm{~g}$ of ABS and HIPS were dissolved in $25 \mathrm{~mL}$ of acetone and toluene, respectively, and by ultracentrifugation at $20,000 \mathrm{rpm}$ for $45 \mathrm{~min}$ and $-20^{\circ} \mathrm{C}$, the gel content (insoluble fraction) was extracted. The soluble fraction was precipitated from methanol and both fractions were dried under vacuum at $50^{\circ} \mathrm{C}$ to constant weight. The gel content in percentage was obtained gravimetrically and the GD was determined

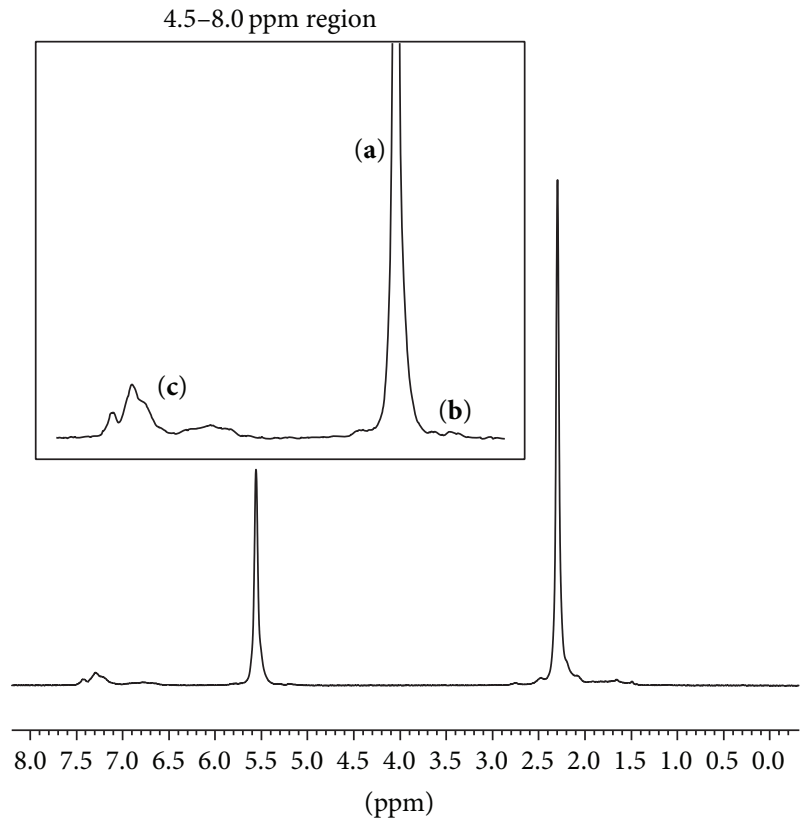

Figure $1:{ }^{1} \mathrm{H}$ NMR spectrum, run 7.

taking into account the difference between the gel content and rubber content, in both cases, HIPS and ABS.

2.7. Transmission Electron Microscopy (TEM). The morphological development of ABS and HIPS was observed with a TEM equipment JEOL at $10 \mathrm{kV}$ on samples cut with a LEICA ULTRACUT ultramicrotome and treated with osmium tetra oxide.

2.8. Differential Scanning Calorimetry (DSC). DSC thermograms were obtained using a TA Instruments, DSC 2920. The analyses were carried out under nitrogen atmosphere using a heating rate of $5^{\circ} \mathrm{C} / \mathrm{min}$ from -150 to $110^{\circ} \mathrm{C}$ and each sample was run twice in order to eliminate the thermal history.

2.9. Dynamic Mechanical Analysis (DMA). Storage modulus and $\tan$ delta were measured on compression-molded specimens of $45 \mathrm{~mm} \times 12.2 \mathrm{~mm} \times 3.2 \mathrm{~mm}$ on a dynamic mechanical analyzer TA Instrument, in flexural mode at a frequency of $0.1 \mathrm{~Hz}$, and with a temperature range from 


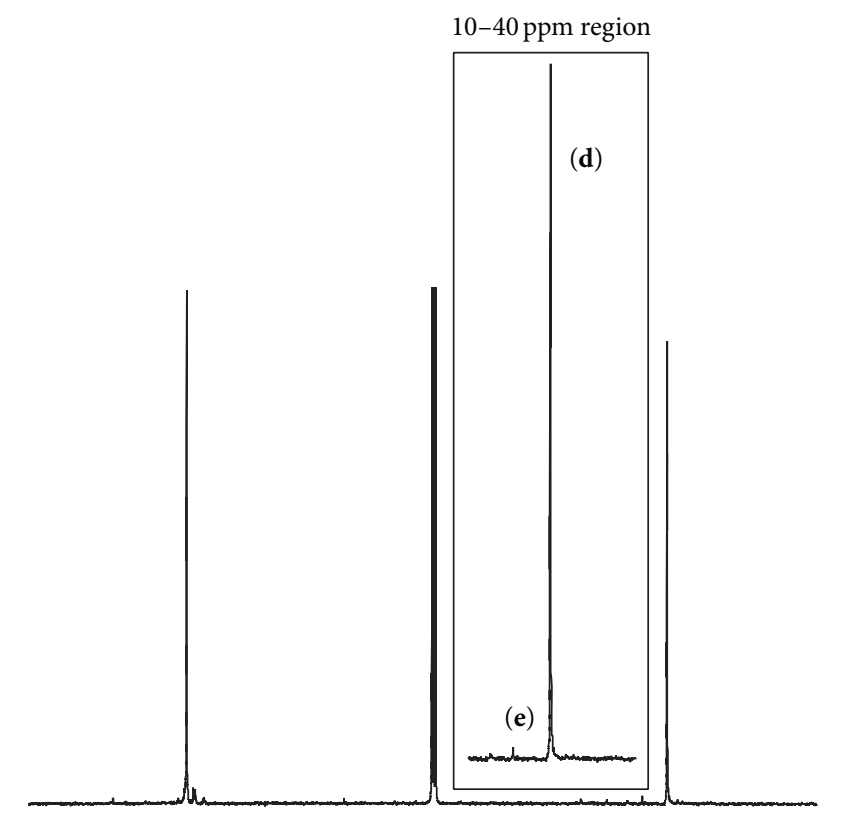

$16015014013012011010090 \quad 80 \quad 70 \quad 60 \quad 50 \quad 40 \quad 30 \quad 20 \quad 10 \quad 0$ (ppm)

Figure 2: ${ }^{13} \mathrm{C}$ NMR spectrum, run 7.

-155 to $110^{\circ} \mathrm{C}$. During the measurement the heating rate was $5^{\circ} \mathrm{C} / \mathrm{min}$ and the amplitude was $0.5 \mathrm{~mm}$.

2.10. Impact Strength Testing. Notched Izod impact strength tests were carried out according to ASTM-256 at $25^{\circ} \mathrm{C}$ on compression-molded specimens of $60.5 \times 12.2 \times 3.2 \mathrm{~mm}$ and depth of notch was $2 \mathrm{~mm}$. The impact was measured using a CSI 137 impact testing machine.

\section{Results and Discussion}

\subsection{1,3-Butadiene Polymerization in Styrene}

3.1.1. Catalyst Activation. The catalyst activation for 1,3butadiene polymerization in styrene solution was performed by in situ and ageing preformation processes. In the first case, each component was introduced into the reactor, while in the second case the catalyst system was prepared 3 min prior to use. Comparing R2 with R6 and R3 with R8 (Table 1) it can be seen that the MWD decreases slightly with the catalyst preformation, although the main effect of the catalyst activation is to reduce the PS content. The catalyst activation through preformation is a process that allows more controlled steps both in alkylation and in chlorination which can lead to an increased concentration of soluble active sites and also helps to prevent agglomeration of $\mathrm{NdCl}_{3}$ particles. Thus, the formation of active sites is more homogeneous which leads to a narrower MWD. Due to the higher MWD, the catalyst activation by in situ process seems to favor the formation of heterogeneous catalytic species consisting of insoluble solid particles of $\mathrm{NdCl}_{3}$. These solid particles, forming a complex

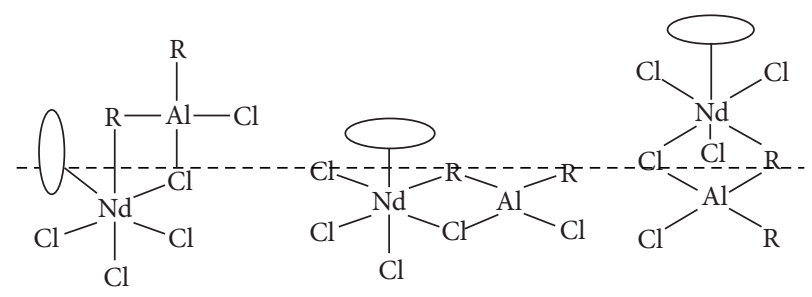

(a)

(b)

(c)

FIgURE 3: Exposition of the available active sites in solid particles for coordination with monomer.

with $\mathrm{AlR}_{3}$, exhibit three different structures available for coordination with the monomer (see Figure 3) [14], where the structure of Figure 3(c) could be the one responsible for the increase in the amount of PS. This may simply be because this coordinate structure permits easier access of the styrene monomer to the active sites of the catalyst. The cis- 1,4 content obtained (around 96\%) was shown to be not dependent on the way of activation of the catalyst system.

3.1.2. Addition Order of Components. The effect of the addition order of components without catalyst activation can be established by comparing R1, R4, and R5. First of all, when adding the components in the order, $\mathrm{S}+\mathrm{B}+\mathrm{Cl}+\mathrm{Nd}+\mathrm{Al}(\mathrm{R} 4)$, the coordination polymerization of 1,3 -butadiene in styrene was not possible. But when EASC (or $\mathrm{Cl}$ ) was added, the reaction temperature increased in an uncontrolled manner, reaching values of $120^{\circ} \mathrm{C}$ in five min and the principal product obtained was essentially PS with an average weight molecular weight $=12,000 \mathrm{~g} / \mathrm{mol}$ and a polydispersity index $(\mathrm{PDI})=$ 2.2. In this case, the EASC acted as Lewis acid catalyst. On the other hand, when the 1,3-butadiene is added at the end, $\mathrm{S}+\mathrm{Al}+\mathrm{Nd}+\mathrm{Cl}+\mathrm{B}(\mathrm{R} 6)$, as compared to $\mathrm{S}+\mathrm{B}+\mathrm{Al}+\mathrm{Nd}+\mathrm{Cl}(\mathrm{R} 1)$, leads to an increase in conversion and a decrease in the PDI and in the PS content, as well as an increase in the molecular weight. According to Friebe et al. [15], the reaction between $\mathrm{NdV}_{3}$ and DIBAH produces $\mathrm{Nd}$ hydride species that can react with 1,3-butadiene monomer to form $\mathrm{Nd}$ allyl species, which are involved in the chlorination process with EASC to form active species. Taking into account that in our case the solvent is styrene monomer, the first insertion of butadiene and subsequent chlorination could be affected by the presence of styrene monomer due the competitive coordination of 1,3-butadiene and styrene to Nd hydride species [6]. This event could increase the amount of PS (R1) and produce active species with different catalytic activity, producing broader MWD. The formation of active species with the addition of 1,3-butadiene at end (R5) (where there is no competitive coordination between styrene and 1,3butadiene to vacant $\mathrm{Nd}$-sites) seems to be more homogeneous and shows narrower MWD.

In another set of experiments, the effect of the addition order of the catalyst components carrying out the ageing preformation process, along a period of $3 \mathrm{~min}$, can be evaluated. Comparing R6 with R7 and R8 with R9, using the preformation addition orders $\mathrm{Al}+\mathrm{Nd}+\mathrm{Cl}(\mathrm{R} 6$ and $\mathrm{R} 8)$ and 


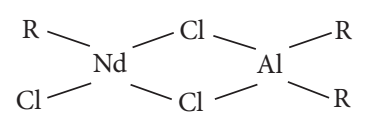

(a) AS-I

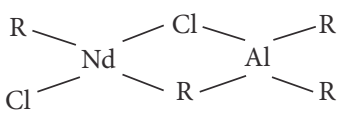

(b) AS-II

Figure 4: Active sites in 1,3-butadiene polymerization using Nd-based catalyst.

$\mathrm{Cl}+\mathrm{Nd}+\mathrm{Al}$ ( $\mathrm{R} 7$ and $\mathrm{R} 9$ ), it can be seen that, in both cases, the conversion is favored with the addition order $\mathrm{Cl}+\mathrm{Nd}+\mathrm{Al}$. The PDI and the molecular weight both increase, whereas the PS content tended to increase. In general, the cis- 1,4 content is not affected by varying the addition order in the ageing preformation process, although at higher $[\mathrm{Al}] /[\mathrm{Nd}]$ ratios $(\mathrm{R} 8$ and R9) the cis-1,4 content diminishes. This behavior will be later discussed.

In the addition order $\mathrm{Cl}+\mathrm{Nd}+\mathrm{Al}$, the EASC first reacts with $\mathrm{Nd}$ and a precipitate is formed consisting of finely dispersed $\mathrm{NdCl}_{3}$, which when reacting with DIBAH promotes the formation of solid particles consisting of bimetallic complexes [16] (structures shown in Figure 3) capable of generating broad MWD (see PDI in R7 and R9). Nevertheless, since the reaction occurs in a heterogeneous phase, only part of $\mathrm{NdCl}_{3}$ is involved in the alkylation and therefore in the formation of active sites. This reduction in the amount of active sites results in an increase in molecular weight as shown in R7 and R9. On the contrary, the addition order $\mathrm{Al}+\mathrm{Nd}+\mathrm{Cl}$ results in soluble catalyst species leading to a narrower MWD (see PDI in R6 and R8).

It is important to mention that even the MWD produced by the addition order $\mathrm{Al}+\mathrm{Nd}+\mathrm{Cl}$, exhibit also two distinct populations (Figure 4) caused by two different active species. According to Manuiko et al. [17] two active sites, namely, ASI and AS-II (see Figure 5), can be created in the activation process, although a transformation of AS-I (centers with the higher activity) to AS-II (centers with lower activity) can also occur in the polymerization as a result of reaction between AS-I and $\mathrm{AlR}_{3}$. AS-I and AS-II have different catalytic activity, stability, and chain transfer properties; at the beginning of the reaction the active sites of both types have participation and form a bimodal MWD; however, at the end of the reaction the polymerization mainly occurs with AS-II and the MWD is unimodal.

Tracht and Kloppenburg [18] reported that two types of active centers are involved in the Nd-catalyzed polymerization of 1,3-butadiene. One of these types produces low molecular weight fractions, and when conversion increases, the molecular weight also increases. In this case, the $\mathrm{Nd}$ catalyst active center promotes a slow chain growing in a steady quasiliving manner with stable soluble active sites [19]. The other type produces higher molecular weight fractions and shows a constant molecular weight regardless of the 1,3-butadiene conversion. In this case, it presents a fast chain growing with the formation of $\mathrm{Nd}$ agglomerates or even heterogeneous insoluble catalyst fractions. However, considering the results reported by Manuiko and Ursula, the active species AS-I together with the $\mathrm{Nd}$ agglomerates or heterogeneous insoluble catalyst (see Figure 3) could contribute to producing high molecular weight populations, whereas AS-II could be

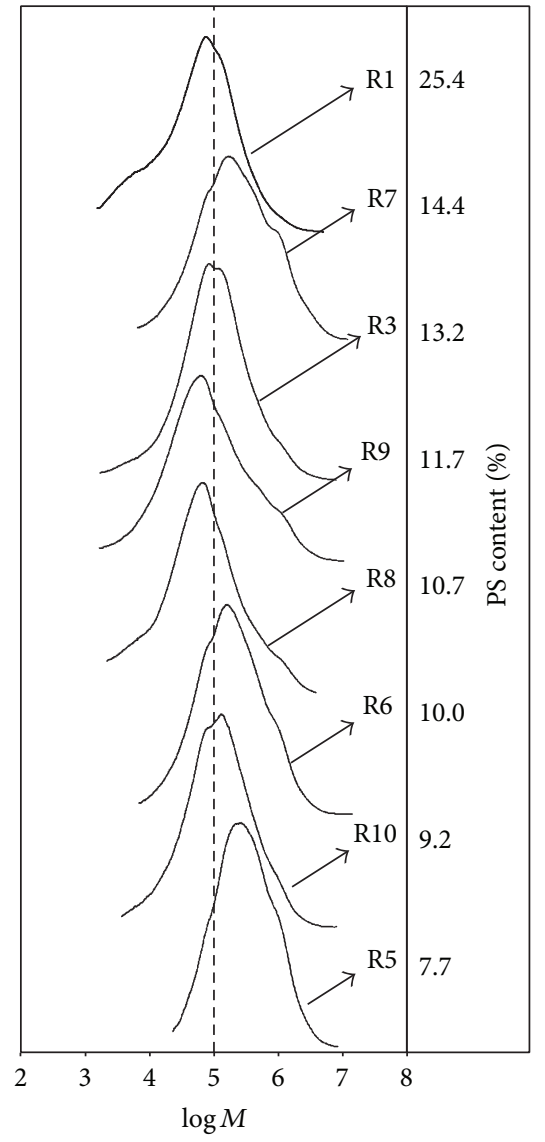

Figure 5: Molecular weight distribution curves for different runs.

responsible for generating low molecular weight populations when the addition order to perform the catalyst system is $\mathrm{Al}+\mathrm{Nd}+\mathrm{Cl}$, as in $\mathrm{R} 6$ and $\mathrm{R} 8$.

3.1.3. Effect of $[\mathrm{Al}] /[\mathrm{Nd}]$ and $[\mathrm{Cl}] /[\mathrm{Nd}]$ Ratios. In all cases when the $[\mathrm{Al}] /[\mathrm{Nd}]$ ratio was increased (R2 versus $\mathrm{R} 3, \mathrm{R} 7$ versus R8, and R7 versus R9), a decrease in conversion, an increase in PDI (see MWD in Figure 4), and a decrease in the molecular weight were observed. In addition, the PS content showed a tendency to decrease with increasing the $[\mathrm{Al}] /[\mathrm{Nd}]$ ratio. The decrease in conversion and PS content due to an increase in $[\mathrm{Al}] /[\mathrm{Nd}]$ ratio from 20 to 30 is in agreement with Zhang et al. [20] who carried out the copolymerization of 1,3-butadiene with styrene in equimolar concentrations using the catalyst system $\mathrm{NdV}_{3} / \mathrm{TIBA} / \mathrm{CHCl}_{3}$. Such behavior was attributed to a change of active site, which might only contain active sites for the polymerization of 1,3-butadiene. This interpretation seems to be related with the conversion of 
ASI to AS-II (Figure 4(b)) during the polymerization, which depends directly on $\mathrm{AlR}_{3}$ concentration, so that at higher $[\mathrm{Al}] /[\mathrm{Nd}]$ ratio AS-II could lose activity by the competitive coordination between 1,3-butadiene and styrene, with lower incorporation of styrene; thus both the conversion and PS content decrease (see R3, R8, and R9). On the other hand, in all cases, the decrease in molecular weight and the corresponding increase in PDI (at higher $[\mathrm{Al}] /[\mathrm{Nd}]$ ratio) denote a remarked chain transfer reaction to DIBAH as reported by Quirk et al. [21]. The increase in the [Al]/[Nd] ratio does not affect the cis-1,4 content (96.1\%) when the catalyst activation was performed by in situ process. However, with the ageing process of catalyst system the cis-1,4 content tends to decrease.

In the catalyst ageing process the formation of active species occurs more rapidly because the concentrations of the catalysts components are usually higher than in the "in situ" process, [22] and that is why a different effect on microstructure should be expected. In this sense, the decrease in the content of microstructure cis-1-4 at higher [Al]/[Nd] ratios using the preformation process can be explained considering that an excess of DIBAH could reduce the number of available coordination sites [15]; therefore $\eta^{4}$-coordination of 1,3-butadiene is reduced resulting in a decrease of the cis-1,4 content.

On the other hand, increasing the $[\mathrm{Cl}] /[\mathrm{Nd}]$ ratio from 0.62 to 0.90 (R8 versus R10) the conversion increases and the PS content decreases slightly. In addition, the molecular weight shows a slight increase, but the PDI is not affected. The increase in conversion can be explained considering that at high halide level a higher number of active sites will be generated. In addition, the higher molecular weights could be attributed to the formation of agglomerates of insoluble $\mathrm{NdCl}_{3}$ particles due to excessive chlorination [23]. Finally, the cis-1,4 content shows an increase when the $[\mathrm{Cl}] /[\mathrm{Nd}]$ ratio is increased [15] in agreement with the literature.

According to Table 1, the glass transition temperatures $\left(T_{g}\right)$ obtained were in the range from -103.3 to $-107.4^{\circ} \mathrm{C}$. Figure 6 shows the thermograms as a function of the PS content for the different materials obtained. It is clearly seen that the typical melting endotherm peak of a high cis- $\mathrm{PB}$ gradually appears as the PS content decreases. This suggests that the PS produced is incorporated into the backbone of $\mathrm{PB}$, which in large amounts seems to have the ability to inhibit the development of typical crystal structures in high cis-1,4 PB [24]. However, as the amount of PS decreases the material begins to exhibit two melting endotherms which are associated with polymorphism (capability of a rubber to crystallize in more than one crystallographic form). In this respect, it has been reported that the first melting endotherm is related to a solid-to-solid transition from a monoclinic form to a hexagonal form, while the second melting endotherm is part of the melting of a hexagonal form [25]. Nevertheless, this has not been published before for structures (copolymers) containing principally high cis-1,4 PB.

To carry out the in situ bulk polymerizations of styrenic resins, two reaction conditions were selected (R5 and R8) and

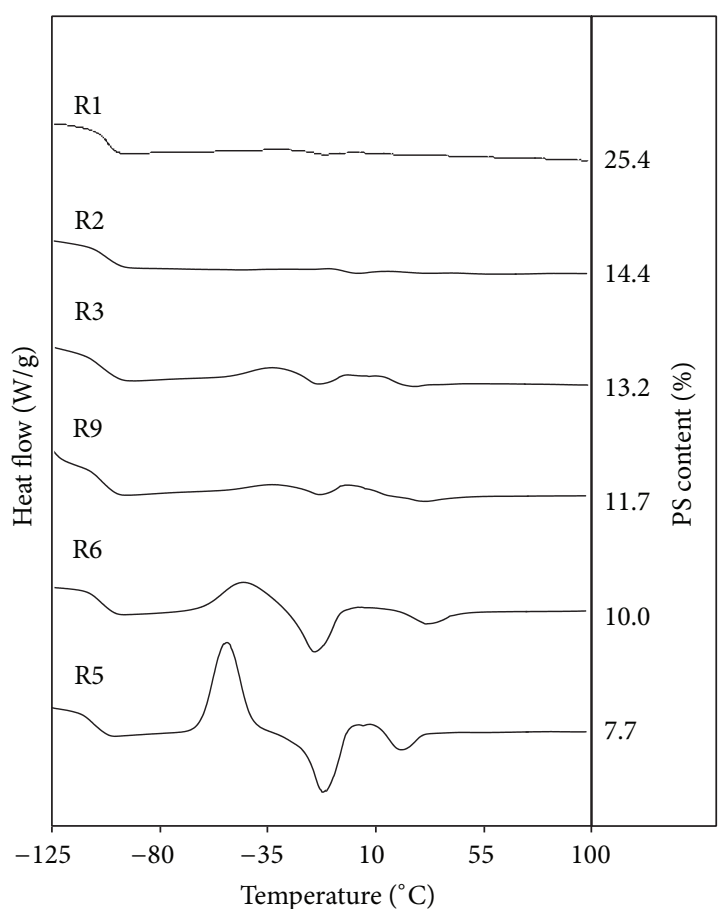

FIGURE 6: Differential scanning calorimetry for different runs varying the polystyrene content.

in order to obtain sufficient amount of high cis-1,4 PB/styrene solution, the amount of reagents was triplicated (see R11 and R12 in Table 1). It is important to mention that the selection of the reaction conditions was made considering the PS content and its molecular weight in addition to the conversion. So R11 was selected for use in ABS considering that a lower PS content (in the high cis-1,4 PB) could benefit the final properties due the better compatibility with the styreneacrylonitrile copolymer (SAN) matrix [8]. Meanwhile, R12 was used in HIPS due to the intermediate values of PS content and molecular weight. The results of characterization of R11 and R12 are shown in Table 1 and it can be seen that there exists a reasonable agreement with R5 and R8. Finally, Figures 7 and 8 show the evolution of composition and conversion as a function of the reaction time for R11 and R12. It can be appreciated that, from the beginning of the polymerization reaction, the PS is formed and its concentration increases slightly with the reaction time. Figure 8 (b) shows the plots of $\ln (1-x)$ versus time for R11 and R12, where a linear relationship can be seen in both cases, indicating that the polymerization rate can be described by first-order kinetics with respect to the 1,3-butadiene concentration.

\subsection{In Situ Bulk Polymerizations to Produce ABS and HIPS.}

Tables 2 and 3 present several molecular parameters and mechanical properties of ABS and HIPS. In the synthesis of $\mathrm{ABS}$, the rubber corresponding to R11, with varying initiator concentration, was used. The average molecular weight of the SAN matrix decreases, as it was expected with the initiator concentration. Also, when the initiator interacts with the rubber, as is the case of the luperox-256, an increase in its 


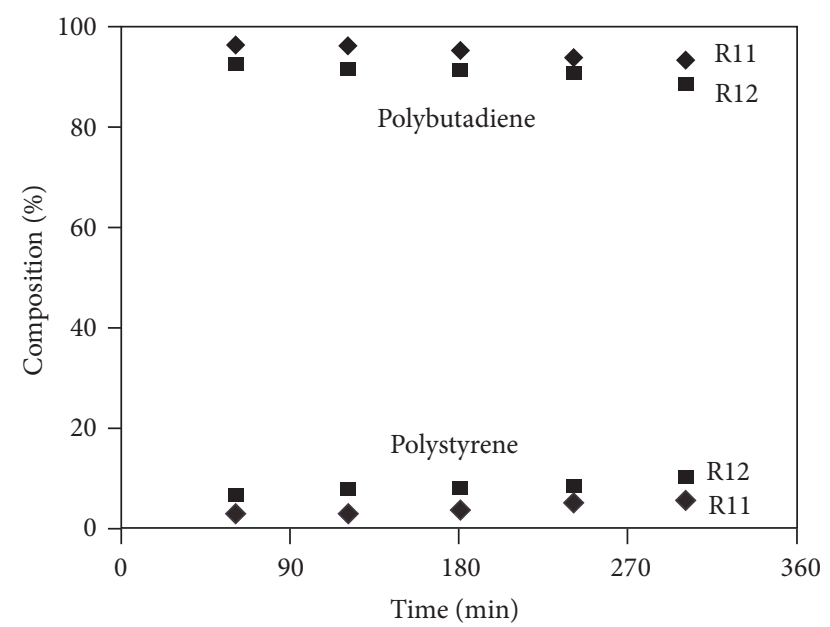

FIgURE 7: Evolution of composition as a function of time in 1,3butadiene coordination polymerization with the catalyst system $\mathrm{NdV}_{3} /$ DIBAH/EASC.

concentration promotes an increase in the amount of grafted SAN, as can be seen from the values of grafting degree. This fact leads to greater stabilization in the morphological development and generates elastomeric defined particles with multiple occlusions of SAN (see ABS-2 in Figure 9). Conversely, with a lower grafting degree, an undefined and elongated morphology, containing occlusions of SAN, is produced. Small values in gel content and GD were observed due to the core-shell and lamellar morphologies obtained which had never before been reported for HIPS using high cis-1,4 PB but are typical in HIPS when using styrene/butadiene block copolymers [26]. The addition of 5\% of PS homopolymer at the beginning of the polymerization in HIPS-2 was carried out in order to identify potential morphological changes. This resulted in a bimodal morphology consisting of coreshell and labyrinth. These morphological changes could be associated with an increase in the interfacial tension between phases and the modification in the viscosities ratio of the phases $\left(\eta_{\text {St-PS }} / \eta_{\text {St-PB }}\right)$ [27]; thus the low molecular weight PS homopolymer added at the beginning provokes a decrease in $\eta_{\mathrm{St}-\mathrm{PS}} / \eta_{\mathrm{St}-\mathrm{PB}}$ and therefore the morphology changes to bimodal.

Figure 9 shows the dynamic mechanical behavior as a function of temperature and the morphology developed for ABS and HIPS, respectively. In the ABS-1 and ABS- 2 curves (Figure 9), three important relaxations are observed, the first presented at low temperatures around $-80^{\circ} \mathrm{C}$ and the second around $-35^{\circ} \mathrm{C}$ and the last exhibited around $90^{\circ} \mathrm{C}$. The first two relaxations are assigned to the high cis-1,4 PB containing $6.3 \%$ of PS (Run 11 in Table 1), where the first relaxation corresponds to the $\mathrm{PB} T_{g}$, while the second one is associated with the relaxation process of the crystalline domains. The last relaxation around $90^{\circ} \mathrm{C}$ is assigned to the alpha relaxation of the SAN matrix according to $\mathrm{Yu}$ et al. [10]. In the case of the HIPS-1 and the HIPS-2 curves, the transition corresponding to the crystalline phase disappears and corroborates the observed through DSC (Figure 8), where an amount of PS in the order of $11 \%$ had

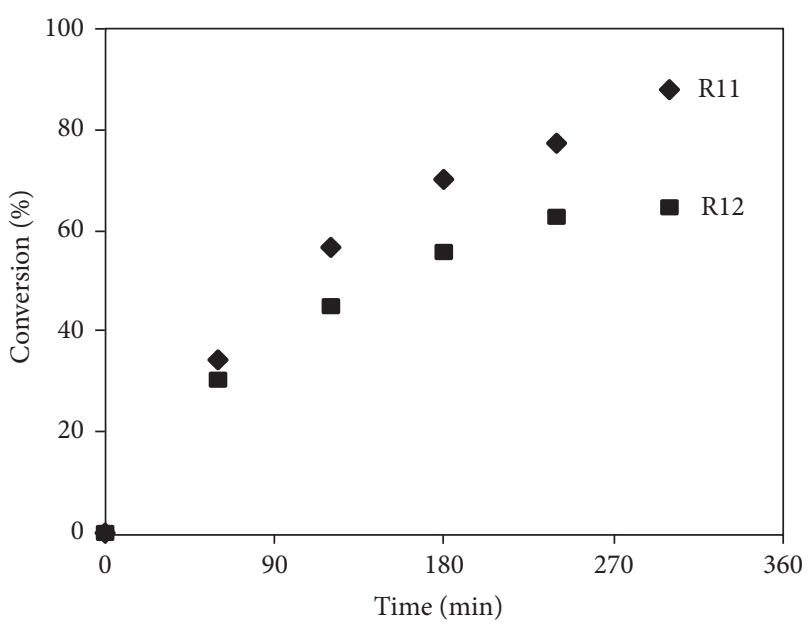

(a)

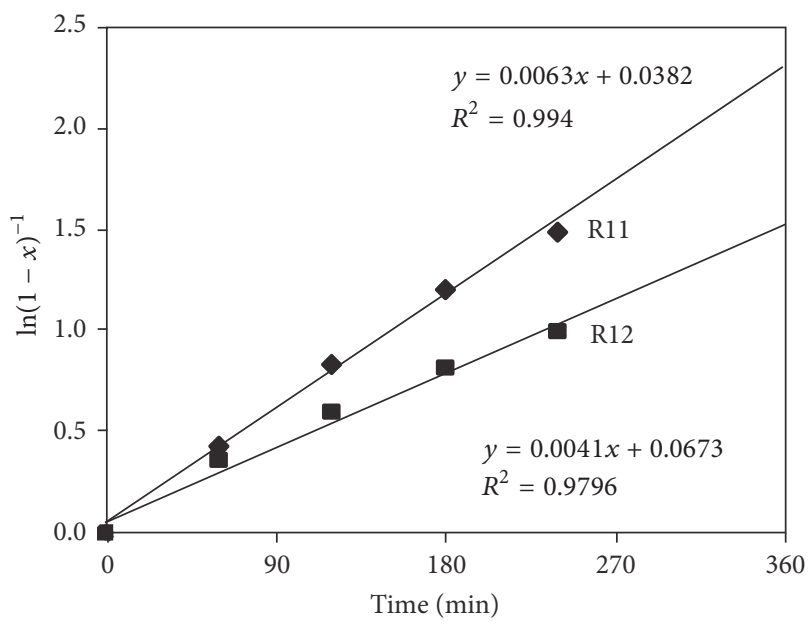

(b)

FIgURE 8: Conversion and first-order plots in 1,3-butadiene coordination polymerization with the catalyst system $\mathrm{NdV}_{3}-50 / \mathrm{DIBAH} /$ EASC.

the capacity to suppress the ability to crystallize in the high cis-1,4 PB, leading to almost complete disappearance of the endotherm peak corresponding to the melting process. HIPS1 presents only corresponding $T_{g}$ of the elastomeric dispersed phase and the continuous phase of PS, whereas HIPS-2 exhibits another relaxation near $-10^{\circ} \mathrm{C}$ in addition to the two previously described in HIPS-1. This secondary relaxation could be related to the distinct generated morphologies, which arise from the different PS-Rubber interfacial interactions. Finally, the low impact strength in both systems ABS and HIPS can be attributed to the reaction conditions used (mainly low rubber concentration) which are subject to optimization in a future work.

\section{Conclusions}

Using the catalyst system $\mathrm{NdV}_{3} / \mathrm{DIBAH} / \mathrm{EASC}$ for the 1,3butadiene coordination polymerization, with styrene as 


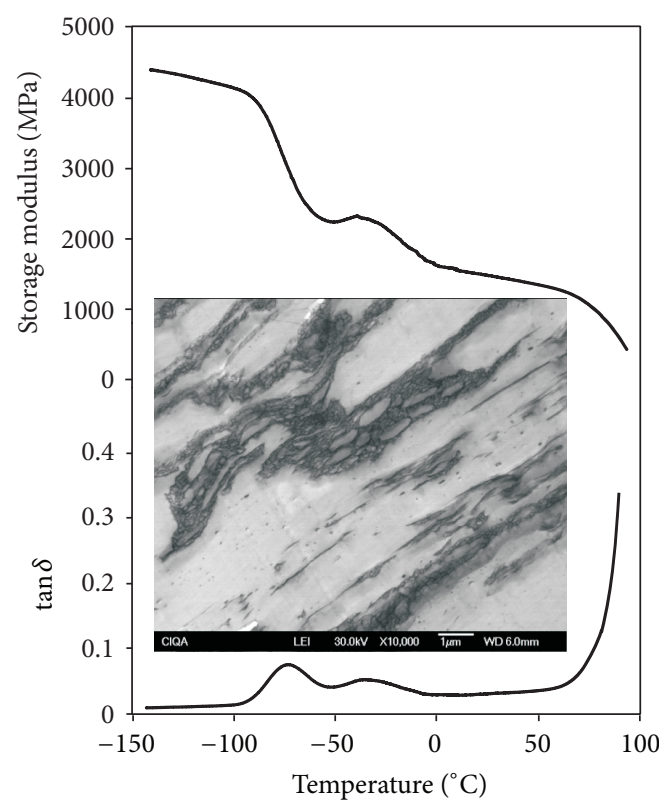

(a) ABS-1

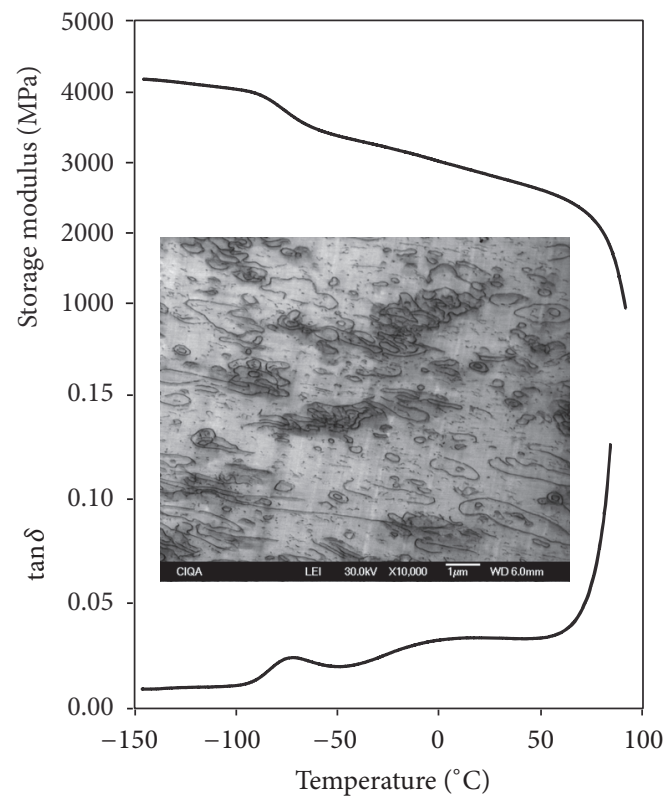

(c) HIPS-1

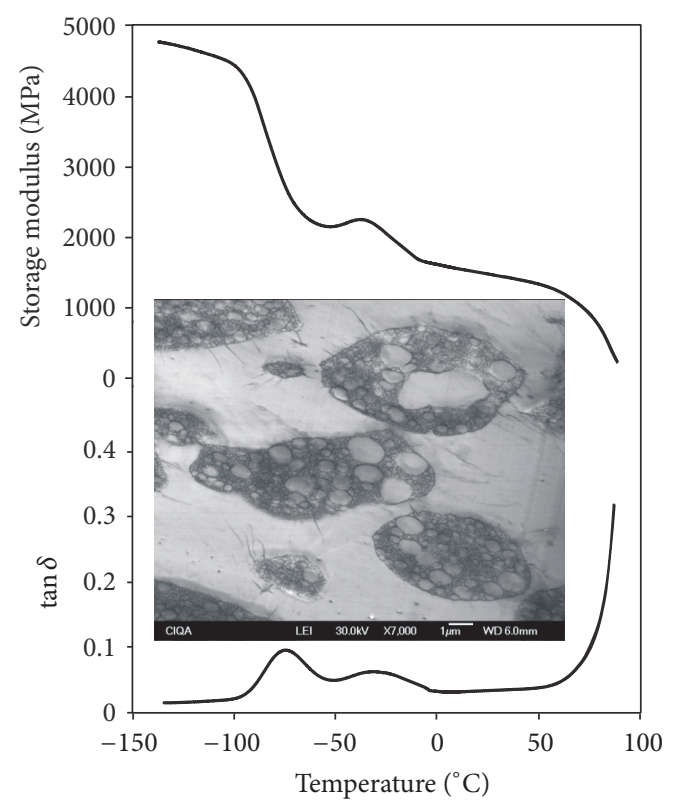

(b) ABS-2

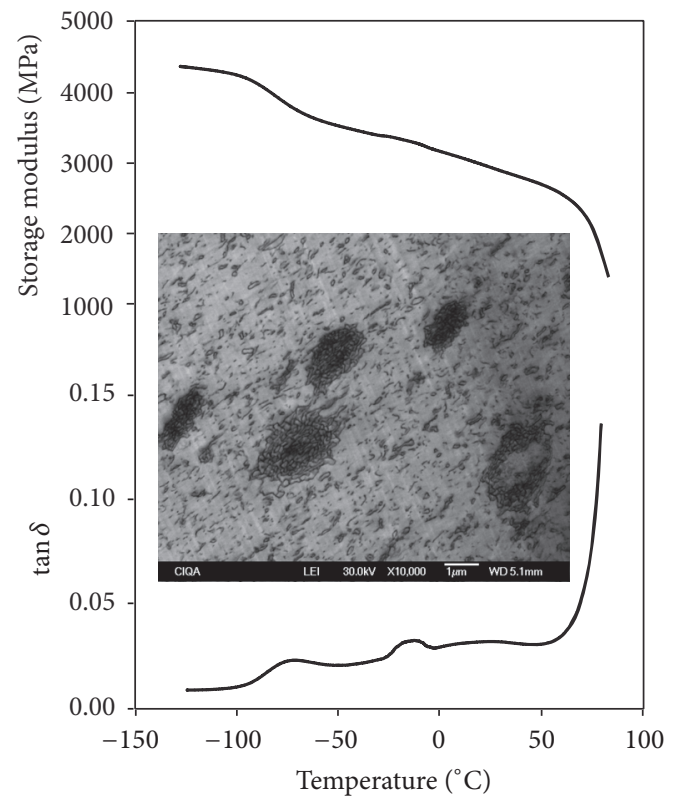

(d) HIPS-2

FIGURE 9: Variation of the storage modulus and $\tan \delta$ as a function of temperature for different ABS and HIPS.

solvent, and varying the catalyst activation, the order of addition of catalyst components, and the $[\mathrm{Al}] /[\mathrm{Nd}],[\mathrm{Cl}] /[\mathrm{Nd}]$ molar ratios, it was possible to achieve conversions between 57.5 and $88.1 \%$. In addition, the incorporation of PS could be predetermined from 6.3 to $15.4 \%$. The glass transition temperatures in the high cis-1,4 PB obtained were in the range from -101.9 to $-107.4^{\circ} \mathrm{C}$ and, depending on the PS content, the high cis-1,4 PB did not exhibit the typical melting endotherm. The use of solutions of styrene/high cis-1,4 PB, varying among them in PS content and molecular weight, allows the synthesis by in situ bulk polymerizations of ABS and HIPS.
In the synthesis of $\mathrm{ABS}$, using the high cis-1,4 $\mathrm{PB}$ with lower PS content, the morphological development consisted of particles with multiple occlusions, whereas the synthesis of HIPS, where high cis-1,4 PB with higher PS content were used, permitted the formation of core-shell, labyrinths, and lamellar morphologies typical of styrene/butadiene block copolymer.

\section{Competing Interests}

The authors declare that there are no competing interests. 


\section{Acknowledgments}

The authors thank José Díaz Elizondo, Jesús Cepeda, Guadalupe Mendez, Mario Palacios, Uriel Peña, and Judith Cabello for their technical support in characterization. Also authors Gabriela Bosques Ibarra and Patricia de León Martínez wish to thank CONACYT for granting them both a scholarship to carry out their Masters degree, from whose work this manuscript is derived.

\section{References}

[1] R. E. Díaz de, F. J. León-Gómez, H. Maldonado-Textle et al., "Synthesis and characterization of high cis-polymyrcene using neodymium-based catalysts," The Canadian Journal of Chemical Engineering, vol. 94, no. 5, pp. 823-832, 2016.

[2] W. Dong, K. Endo, and T. Masuda, "Effect of tert-butyl chloride on the isoprene polymerization with neodymium isopropoxide/diisobutylaluminum hydride and neodymium isopropoxide/methylaluminoxane catalysts," Macromolecular Chemistry and Physics, vol. 204, no. 1, pp. 104-110, 2003.

[3] F. Wang, H. Liu, W. Zheng et al., "Fully-reversible and semireversible coordinative chain transfer polymerizations of 1,3butadiene with neodymium-based catalytic systems," Polymer, vol. 54, no. 25, pp. 6716-6724, 2013.

[4] N. V. Duvakina and Y. B. Monakov, "Unusual influence of the preparation conditions of neodymium-magnesium catalyst systems on their stereospecificity in butadiene polymerization," Doklady Chemistry, vol. 384, no. 1-3, pp. 129-131, 2002.

[5] V. Monteil, R. Spitz, and C. Boisson, "Polymerization of butadiene and copolymerization of butadiene with styrene using neodymium amide catalysts," Polymer International, vol. 53, no. 5, pp. 576-581, 2004.

[6] L. Friebe, J. M. Müller, O. Nuyken, and W. Obrecht, "Comparison of the solvents $n$-hexane, tert-butyl benzene and toluene in the polymerization of 1,3-butadiene with the Ziegler catalyst system neodymium versatate/diisobutylaluminum hydride/ethylaluminum sesquichloride," Journal of Macromolecular Science Part A: Pure and Applied Chemistry, vol. 43, no. 6, pp. 841-854, 2006.

[7] H. L. Hsieh and H. C. Yeh, "Polymerization of butadiene and isoprene with lanthanide catalysts; characterization and properties of homopolymers and copolymers," Rubber Chemistry and Technology, vol. 58, no. 1, pp. 117-145, 1985.

[8] Y. Hu, Z. Jia, Y. Li, L. Chang, and Y. Wang, "Synthesis and impact properties of in situ bulk made ABS resins toughened by high cis-1,4 polybutadiene," Materials Science and Engineering A, vol. 528, no. 22-23, pp. 6667-6672, 2011.

[9] Y. Hattori and Y. Kitagawa, "Prepolymerization process for producing a conjugated diene compound prepolymer solution," US Patent Appl. 5096970, 1992.

[10] Z. Yu, Y. Li, Y. Wang et al., "Morphological, mechanical properties, and fracture behavior of bulk-made ABS resins toughened by high-cis polybutadiene rubber," Polymer Engineering and Science, vol. 50, no. 5, pp. 961-969, 2010.

[11] J. Rovere, C. A. Correa, V. G. Grassi, and M. F. D. Pizzol, "Role of the rubber particle and polybutadiene cis content on the toughness of high impact polystyrene," Journal of Materials Science, vol. 43, no. 3, pp. 952-959, 2008.

[12] H. Windisch, T. Schnieder, G. Michels et al., "Method for polymerizing conjugated diolefins (dienes) with catalysts of rare earths in the presence of vinyl aromatic solvents," US Patent Appl. $20040030071 \mathrm{A1}, 2004$.

[13] R. D. De Leõn, M. T. A. Cõrdova, F. J. E. Medrano et al., "Polymerization of 1,3-butadiene with several catalytic systems based on neodymium or lithium in presence of ionic liquids," Macromolecular Symposia, vol. 325-326, no. 1, pp. 194-202, 2013.

[14] I. L. Mello and F. M. B. Coutinho, "Neodymium Ziegler-Natta catalysts: evaluation of catalyst ageing effect on 1,3-butadiene polymerization," European Polymer Journal, vol. 44, no. 9, pp. 2893-2898, 2008.

[15] L. Friebe, O. Nuyken, H. Windisch, and W. Obrecht, "Polymerization of 1,3-butadiene initiated by neodymium versatate/diisobutylaluminium hydride/ethylaluminium sesquichloride: kinetics and conclusions about the reaction mechanism," Macromolecular Chemistry and Physics, vol. 203, no. 8, pp. 10551064, 2002.

[16] G. Ricci, S. Italia, F. Cabassi, and L. Porri, "Neodymium catalysts for 1,3-diene polymerization: influence of the preparation conditions on activity," Polymer Communications Guildford, vol. 28, no. 8, pp. 223-226, 1987.

[17] G. V. Manuiko, I. I. Salakhov, G. A. Aminova et al., "Mathematical modeling of 1,3-butadiene polymerization over a neodymium-based catalyst in a batch reactor with account taken of the multisite nature of the catalyst and chain transfer to the polymer," Theoretical Foundations of Chemical Engineering, vol. 44, no. 2, pp. 139-149, 2010.

[18] U. Tracht and H. Kloppenburg, "Modeling Nd-catalyzed butadiene rubber production," Macromolecular Symposia, vol. 259, pp. 76-84, 2007.

[19] D. J. Wilson and D. K. Jenkins, "Butadiene polymerisation using ternary neodymium-based catalyst systems-the effect of catalyst component addition order," Polymer Bulletin, vol. 27, no. 4, pp. 407-411, 1992.

[20] Q. Zhang, X. Ni, and Z. Shen, "Copolymerization of butadiene with styrene by $\mathrm{Nd}$ (vers) $)_{3}-\mathrm{Al}(\mathrm{i}-\mathrm{Bu})_{3}-\mathrm{CHCl}_{3}$ catalyst system," Journal of Macromolecular Science Part A: Pure and Applied Chemistry, vol. 41, no. 1, pp. 39-48, 2004.

[21] R. P. Quirk, A. M. Kells, K. Yunlu, and J.-P. Cuif, "Butadiene polymerization using neodymium versatate-based catalysts: catalyst optimization and effects of water and excess versatic acid," Polymer, vol. 41, no. 15, pp. 5903-5908, 2000.

[22] A. Oehme, U. Gebauer, K. Gehrke, P. Beyer, B. Hartmann, and M. D. Lechner, "The influence of the catalyst preparation on the homo- and copolymerization of butadiene and isoprene," Macromolecular Chemistry and Physics, vol. 195, no. 12, pp. 3773-3781, 1994.

[23] D. J. Wilson and D. K. Jenkins, "Butadiene polymerisation using ternary neodymium-based catalyst systems," Polymer Bulletin, vol. 34, no. 3, pp. 257-264, 1995.

[24] F. J. Enríquez-Medrano, L. A. V. López, Y. A. De SantiagoRodríguez et al., "Polymerization of 1,3-butadiene with neodymium chloride tripentanolate/triisobutylaluminum binary catalyst system: effect of aging time and reaction temperature," Journal of Polymer Engineering, vol. 35, no. 2, pp. 105-111, 2015.

[25] M. R. Rivera, R. Herrera Nájera, J. J. Benvenuta Tapia, and L. Ríos Guerrero, "Structure and properties of model polybutadienes-effect of microstructure on the dynamic mechanical properties of rubber," Journal of Elastomers and Plastics, vol. 37, no. 3, pp. 267-278, 2005.

[26] R. Díaz de León, G. Morales, P. Acuña, and F. Soriano, "Phenomenon of phase inversion in high impact polystyrene: 
physico-chemical, rheological and morphological study in the presence of chain transfer agent and using different tapered block copolymers as the precursor rubber," Polymer Engineering and Science, vol. 50, no. 2, pp. 373-383, 2010.

[27] F. Soriano-Corral, G. Morales, P. Acuña et al., "Synthesis and characterization of high impact polystyrene from a heterogeneous styrene-rubber-polystyrene solution: influence of PS concentration on the phase inversion, morphology and impact strength," Macromolecular Symposia, vol. 325-326, no. 1, pp. 177183, 2013. 

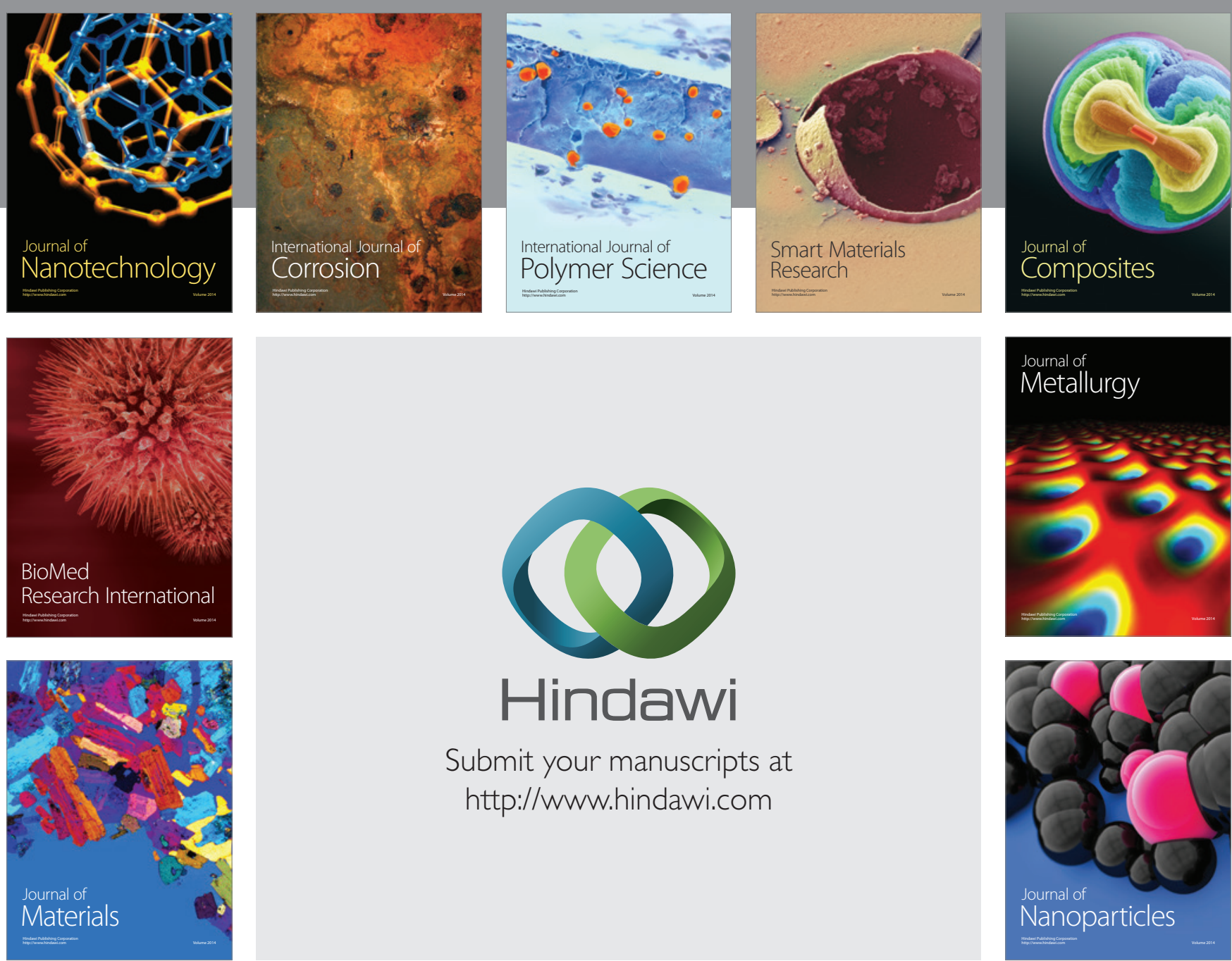

\section{Hindawi}

Submit your manuscripts at

http://www.hindawi.com

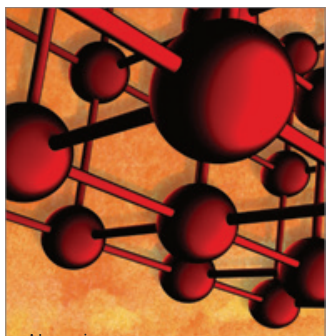

Materials Science and Engineering
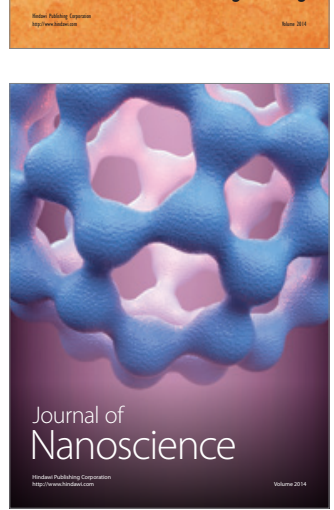
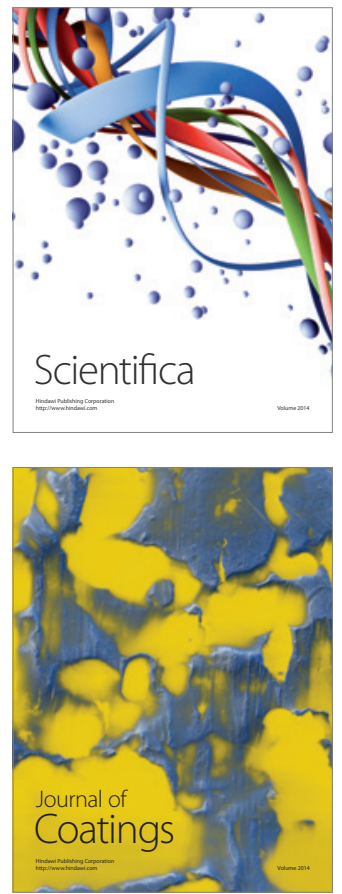
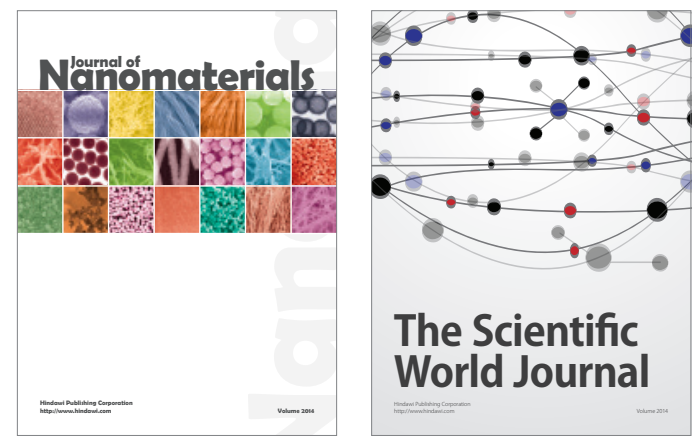

The Scientific World Journal
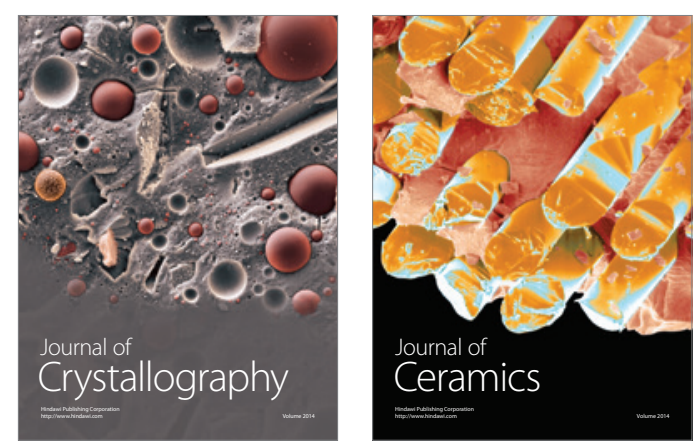
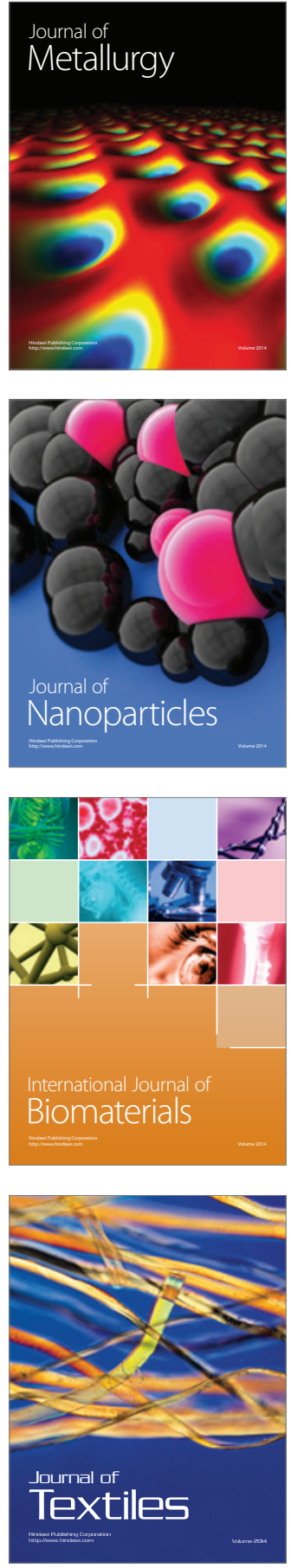